\title{
Producción alternativa del hábitat en el barrio Movediza, Tandil.
}

Nuevas estrategias de acceso al suelo urbano y a la vivienda

\section{Alejandro Migueltorena ${ }^{1}$ \\ Instituto de Geografía, Historia y Ciencias Sociales \\ IGEHCS (UNCPBA/CONICET)}

\section{Artículo Científico}

Material original autorizado para su primera publicación en el Journal de Ciencias Sociales, Revista Académica de la Facultad de Ciencias Sociales de la Universidad de Palermo.

Recepción: 23-05-2020

Aceptación en espera de asignación de número: 23-12-2020

Resumen: En la primera década del siglo XXI, en la ciudad de Tandil se registró un importante crecimiento de la industria de la construcción y de la actividad inmobiliaria, que derivó en una mayor diversificación de los proyectos urbanísticos destinados a los usos residenciales y recreativos. Este proceso estuvo acompañado por una consolidación de los inmuebles como bienes financieros, que promovió movimientos especulativos y generó mayores limitaciones para que la población trabajadora acceda a una vivienda digna. Si bien este es un fenómeno que no se limita sólo al ámbito local, determinadas características de Tandil incidieron para que el auge inmobiliario adquiriera una mayor intensidad que en otras ciudades de la región. En este contexto, surgieron nuevas estrategias de producción de suelo, vivienda e infraestructura urbana, que no eran usuales en la ciudad y que fueron desarrolladas por diferentes actores sociales excluidos del mercado inmobiliario formal, entre los que se incluyeron desde trabajadores asalariados hasta grupos sociales en situación de extrema vulnerabilidad. Estas experiencias se concentraron en algunos lugares específicos del ejido urbano, siendo el barrio Movediza uno de los más destacados. El objetivo de este trabajo consiste en analizar la diversificación de formas de producción del hábitat que se han desarrollado en este barrio de la ciudad de Tandil, en las últimas dos décadas, identificando las nuevas relaciones que se generaron entre la lógica mercantil, la lógica pública y la de las necesidades sociales. Para ello se realizaron entrevistas en profundidad a referentes de las organizaciones y a informantes clave. También se utilizaron datos brindados por la Secretaría de Desarrollo Social del Municipio.

\footnotetext{
1 Doctor en Geografía. Becario Posdoctoral en Temas Estratégicos, CONICET. Centro de Investigaciones Geográficas e Instituto de Geografía, Historia y Ciencias Sociales. Universidad Nacional del Centro de la Provincia de Buenos Aires. Consejo Nacional de Investigaciones Científicas y Técnicas. CIG-IGEHCS (UNCPBA/CONICET). Pinto 399, (7000) Tandil, Buenos Aires, Argentina.

Correo electrónico: amiguel@fch.unicen.edu.ar
}

pág. 4 
Palabras Clave: lógicas de producción del hábitat; políticas públicas; organizaciones sociales; barrio Movediza.

\section{Alternative habitat production in the Movediza neighborhood, Tandil. New strategies for access to urban land and housing.}

Abstract: In the first decade of the 21 st century, in the city of Tandil there was a significant growth in the construction industry and real estate activity, which led to a greater diversification of urban projects for residential and recreational uses. This process was accompanied by a consolidation of real estate as financial assets, which promoted speculative movements and created greater limitations for the working population to access decent housing. Although this is a phenomenon that is not limited only to the local level, certain characteristics of Tandil influenced the real estate boom to acquire a greater intensity than in other cities in the region. In this context, new strategies for the production of land, housing and urban infrastructure emerged, which were not usual in the city and which were developed by different social actors excluded from the formal real estate market, including from salaried workers to social groups in extremely vulnerable situation. These experiences were concentrated in some specific places in the urban ejido, with the Movediza neighborhood being one of the most prominent. The objective of this work is to analyze the diversification of habitat production forms that have developed in this neighborhood of the city of Tandil, in the last two decades, identifying the new relationships that were generated between the commercial logic, the public logic and that of social needs. To do this, in-depth interviews were conducted with organizations' referents and key informants. Data provided by the Municipality's Department of Social Development were also used.

Keywords: habitat production logics; public politics; Social Organizations; Movediza neighborhood.

\section{Introducción}

Luego de la crisis económica que marcó el fin del modelo de la convertibilidad, en Argentina comenzaron a sentarse las bases para un nuevo ciclo de crecimiento económico que dinamizó fuertemente la industria de la construcción y la actividad inmobiliaria. En este contexto, se produjo una proliferación de inversiones destinadas a la generación de distintos proyectos urbanos, debido a los altos márgenes de ganancias que éstas generaban. Simultáneamente, se observó una importante consolidación del valor financiero de los bienes inmuebles, los cuales aumentaron su valor de manera exorbitante, generando que sectores 
cada vez más amplios de la población trabajadora vean restringida su posibilidad de acceder a una vivienda digna.

En Tandil, este proceso tuvo características singulares, debido al perfil económico que adquirió la ciudad en estos años, donde se percibió un destacado crecimiento del sector turístico y recreativo. Los paisajes serranos, que se encuentran al sur del ejido urbano, fueron especialmente valorizados para el desarrollo de distintos emprendimientos residenciales y de actividades vinculadas al ocio, lo cual promovió la incorporación de tierras al mercado inmobiliario, que rápidamente fueron urbanizadas y puestas a disposición para la realización de estos proyectos.

Sin embargo, el incremento que registraron los precios de los bienes inmuebles fue mucho mayor que el crecimiento que percibieron los ingresos de la población trabajadora, generando que el acceso al hábitat digno por medio del mercado formal fuese cada vez más restrictivo. Frente a esta situación, comenzaron a emerger diferentes estrategias alternativas de producción de suelo, viviendas e infraestructura urbana, que incluyeron desde la conformación de asociaciones civiles para el desarrollo de proyectos residenciales, hasta modalidades más extremas, como la usurpación de terrenos y viviendas que llevaron a cabo los grupos sociales más vulnerables. La mayor parte de estas experiencias de urbanización se concretaron en el barrio Movediza, debido a los bajos valores de las parcelas y a la disponibilidad de tierras fiscales. El objetivo de este trabajo consiste en analizar las diversificación de formas de producción del hábitat que se han desarrollado en este barrio de la ciudad de Tandil, en las últimas dos décadas, identificando las nuevas relaciones que se generaron entre la lógica mercantil, la lógica pública y de las necesidades sociales. Para ello se realizaron entrevistas semiestrucuradas a referentes de las organizaciones que formaron parte de la producción de estos proyectos residenciales. También se entrevistó a una trabajadora de la Secretaría de Desarrollo Social del Municipio y se utilizaron documentos brindados por esta misma institución.

\section{Lógicas de producción del hábitat en las sociedades capitalistas dependientes}

Los antecedentes vinculados al estudio de la producción de la vivienda en las sociedades capitalistas pueden remontarse a los aportes realizados por Engels ([1873] 2006), en los cuales se asevera que el déficit habitacional no constituye un problema coyuntural o momentáneo, sino que resulta un rasgo intrínseco a este modo de producción. De esta forma, el intelectual alemán sostenía que las medidas implementadas para abordar la cuestión del acceso a la vivienda desde el estado burgués sólo conseguían desplazar el problema a otros lugares de la ciudad, ya que la causa originaria de las malas condiciones residenciales de la 
población trabajadora estaba relacionada con la propiedad privada del suelo y de los inmuebles.

En el siglo XX, referentes de la Escuela Francesa de Sociología Urbana también abordaron este problema. Topalov ([1979] 2006) por ejemplo, afirmaba la vivienda desde el momento en que se conforma como una mercancía poseía un valor de uso y un valor de cambio. Es valor de cambio porque es producida por el capital y circula como capital, y también porque a partir de ella es que es posible la valorización de los capitales que se especializan en su producción, es decir, los capitales de la construcción, los inmobiliarios y los bancarios. Pero también se constituye como valor de uso, en tanto es necesario para la reproducción de la fuerza de trabajo. Sin embargo, existe una contradicción, ya que la vivienda constituye un valor de cambio que resulta inaccesible para la mayoría de la población, lo cual representa una limitación para la valorización de los capitales del sector inmobiliario. Al mismo tiempo, es indispensable para la producción capitalista que la mano de obra tenga acceso a este bien, lo cual no puede ser asegurado por el sector inmobiliario, porque que no produce la suficiente cantidad de inmuebles que requieren los trabajadores.

En los distintos momentos históricos, se han brindado diferentes respuestas para abordar estas contradicciones generadas entre la progresiva mercantilización de los distintos aspectos de la vida y la reproducción de las relaciones sociales. Pírez (2014) sostiene que una de las soluciones más comunes ha consistido en la desmercantilización parcial de esas relaciones mediante la intervención del Estado, a partir de la cual se cubren parte de las necesidades de la población trabajadora y, de ese modo, se disminuye el costo de su reproducción social. Según este mismo autor, los procesos de desmercantilización estatal pueden incentivarse, fundamentalmente, por la vía de la producción o del consumo. En el primer caso, implica la suspensión de las reglas de la acumulación del capital en la generación de determinados bienes y servicios esenciales para la población trabajadora y, en el segundo, consiste en la posibilidad de cubrir ciertas necesidades sin erogación monetaria, o abonando un precio que se encuentra por debajo de la estructura de costos y ganancias que rige en el mercado.

Sin embargo, en las sociedades latinoamericanas lo que ha predominado no son los procesos de desmercantilización estatal, sino aquellos relacionados con la desmercantilización social. Esto implica que la población que encuentra restringida su posibilidad de acceder al consumo mercantil produce sus propios bienes, que en el caso específico del hábitat lo realiza por medio de modalidades de autoconstrucción. De esta forma, autores como Pírez (1995) y Abramo (2011), afirman que en el proceso de urbanización capitalista latinoamericano pueden identificarse tres lógicas que intervienen en la producción del hábitat: la mercantil, la pública y la de las necesidades sociales. La primera 
de ellas, se relaciona con aquellas inversiones destinadas a obtener un lucro a través de la concreción de algún tipo de proyecto inmobiliario. Diversos referentes, entre los que se pueden citar a de Mattos (2007), Pírez (2014) y Pradilla Cobos (2014), han estudiado las transformaciones ocurridas en los espacios urbanos de la región a partir de las lógicas adoptadas por el mercado inmobiliario en un contexto de hegemonía de los principios neoliberales.

A su vez, la lógica pública implica, por un lado, la intervención del Estado en la producción de distintas operatorias de vivienda social y, por otro, la implementación de diversas políticas dirigidas a subvencionar la demanda, asegurar los beneficios de las empresas constructoras, o generar infraestructura urbana y espacios residenciales por medio de la implementación de programas de planificación. Con respecto a este tema, se pueden recuperar los aportes de Cliquevsky (2009), sobre las políticas de regulación de tierras informales en América Latina; y también el trabajo de Fernández Wagner (2014), que analiza los resultados de los programas habitacionales que se implementaron en Argentina, en la primera década del siglo XXI.

Por último, la lógica de las necesidades sociales alude a los procesos de autoproducción del hábitat, que jerarquizan el valor de uso del espacio urbano, al constituirlo en el lugar de desarrollo de la vida cotidiana de sus pobladores. Dentro de esta lógica, Rodríguez et al. (2007) incluyen a la Producción Social del Hábitat (PSH), que se caracteriza por constituir un proceso dirigido por algún actor social concreto. Dicho actor debe tener una activa participación en la planificación y en la gestión del proceso, pudiendo estar representado por una organización social, una cooperativa, un sindicato, una ONG o cualquier otro sujeto que trascienda una unidad doméstica que sólo persigue su propia reproducción. A su vez, estas iniciativas incluyen desde el mejoramiento de la infraestructura barrial hasta la construcción de conjuntos habitacionales completos. Por su parte, Ortiz Flores (2012) establece una distinción entre aquello que denomina la autoconstrucción y la producción social, indicando que la primera sólo implica la construcción de la vivienda, o de cualquier otro elemento vinculado al hábitat por parte de quienes serán sus futuros habitantes; mientras que la segunda incluye el control de todas las fases del proceso, que abarca la planificación, la edificación, la distribución y el uso. De esta forma, según el autor, si bien las lógicas privadas, pública y de las necesidades sociales pueden coexistir y complementarse, sólo una de ellas tendrá el control de la integralidad del proceso, por medio de un actor o sujeto concreto.

De acuerdo con Pírez (2016), la heterogeneidad de modalidades de producción y consumo del hábitat que la actualidad se desarrollan en América Latina, pueden comprenderse a raíz del lugar dependiente que la región ocupa en el mercado internacional, 
lo cual determina que se generen procesos productivos con ciertas particularidades y, especialmente, con una limitada capacidad de absorción de fuerza de trabajo. Dicha condición estructural, redunda en que una amplia proporción de la población trabajadora deba acudir a diversos mecanismos no mercantiles para satisfacer sus necesidades básicas. Con el advenimiento de los modelos económicos neoliberales, se reforzó una orientación mercantilista en la producción de la vivienda y los servicios, que provocó un incremento de la población insolvente y una diversificación de las modalidades de producción y consumo de los bienes urbanos.

\section{Modelo de urbanización excluyente y estrategias alternativas de acceso al hábitat en la ciudad de Tandil}

En la primera década del siglo XXI, la economía argentina experimentó un ciclo de recuperación y crecimiento, luego de haber atravesado por la crisis que provocó el estallido del modelo de la convertibilidad, entre los años 2001 y 2002. Este período se caracterizó por la implementación de una serie de medidas que se dirigieron a reconstruir el mercado interno y recuperar los puestos de trabajo que se habían perdido a raíz de la aplicación de políticas de corte neoliberal. A su vez, se registró un importante crecimiento de la industria de la construcción y de las inversiones dirigidas a los bienes inmuebles, en parte debido a la disponibilidad de los flujos de capitales provenientes de sectores que generaban rentas extraordinarias, principalmente vinculados a la producción de commodities para el mercado externo. También colaboró en este proceso el hecho de que las inversiones inmobiliarias, durante estos años, producían ganancias que se encontraban por encima de las que ofrecían otras actividades económicas.

Sin embargo, a pesar de que durante este período se percibió una mejora en los indicadores sociales y económicos, las posibilidades de acceso al hábitat digno para la población trabajadora no mejoraron sustancialmente, e incluso podría considerarse que se incrementaron las dificultades para satisfacer aquellas cuestiones vinculadas con el derecho a la ciudad. Segura (2014) sostiene que esta situación se encuentra relacionada con la continuidad de un modelo de urbanización excluyente que limitó los efectos que pudo generar la redistribución del ingreso que se llevó a cabo en esos años en Argentina y en otros países de la región. De este modo, al no cuestionarse los mecanismos que limitan el acceso al suelo urbano, los procesos de segregación se profundizaron aún en momentos de expansión de la actividad económica. Según Catenazzi y Reese (2013), la progresiva distancia que se registró entre los ingresos de la población trabajadora y el precio del suelo urbano y de los inmuebles, dio como resultado un incremento de la informalidad urbana. De esta manera, si bien existió una preocupación desde el Estado nacional por el desarrollo de una política habitacional de gran alcance, no se establecieron las medidas necesarias para regular el mercado 
inmobiliario y contener los efectos negativos que generó la especulación. Asimismo, el reforzamiento de las lógicas que promovieron la producción del suelo urbano con el fin de valorizar capitales e incrementar la apropiación de rentas, provocaron que el valor de uso de los bienes inmuebles se debilite frente a la preponderancia que adquirió el valor de cambio (del Río, 2014).

Particularmente, en la ciudad de Tandil, durante este mismo período, se evidenció un importante dinamismo de la actividad inmobiliaria y la proliferación de diferentes tipos de proyectos vinculados a los usos residenciales, recreativos y turísticos. De acuerdo a los censos nacionales, entre los años 2001 y 2010, la cantidad de viviendas en la ciudad se incrementó en un 22,8\%, pasando de 41.067 a 50.450 unidades; mientras que en ese mismo período la población creció un 14,6\%, de 108.109 a 123.871 habitantes. No obstante, al analizar el régimen de tenencia de las viviendas, se observa que los propietarios se redujeron de un $70,4 \%$ a un $62,5 \%$, mientras que los inquilinos ascendieron del $15,5 \%$ al $24,5 \%$ (INDEC, $2001,2010)$. Esta tendencia continuó en la década siguiente, ya que según la Encuesta de Hogares y Empleo Municipal, en el año 2018, los propietarios descendieron hasta el 57,6\% y los inquilinos alcanzaron el 30\% (El Eco de Tandil, 21/09/2019). Esta disminución del porcentaje de propietarios puede entenderse a raíz de la valorización que registraron los bienes raíces a lo largo de estos años, la cual estuvo muy por encima del incremento de la capacidad adquisitiva que percibieron los ingresos de la población trabajadora. Asimismo, el Registro Público Provincial de Villas y Asentamientos Precarios (2016), da cuenta de la existencia de siete barrios informales en la ciudad de Tandil, cuatro de los cuales surgieron en las últimas dos décadas y, de estos últimos, dos se ubicaron en el barrio Movediza.

En términos espaciales, este proceso dio lugar a una diferenciación hacia el interior de la ciudad, que acentuó las desigualdades previamente existentes. En la zona céntrica se multiplicaron los edificios en altura, mientras que en el eje sur del ejido urbano proliferaron barrios los cerrados y todo tipo de proyectos vinculados con la actividad turística y recreativa. Por su parte, en las periferias este, norte y oeste se extienden los barrios donde reside la población trabajadora, que en las últimas dos décadas también han registrado un gran crecimiento, debido a los valores relativamente bajos de los precios del suelo. Estos espacios también han sido los destinatarios de las operatorias de conjuntos de vivienda social que se generaron en la década de 2000, ya que allí se encuentran la mayor parte de las tierras fiscales que posee el Municipio. Además, en la década pasada, también se produjo una importante demanda de lotes por parte de los beneficiarios de los créditos Pro.Cre.Ar. ${ }^{2}$

\footnotetext{
${ }^{2}$ El Programa de Crédito Argentino del Bicentenario para la Vivienda Única Familiar (PRO.CRE.AR.) fue implementado en el año 2012 mediante el Decreto №12 del Poder Ejecutivo Nacional.
} 
La consolidación que se generó a lo largo de estos años de los inmuebles como bienes financieros, que resultaron adecuados para la inversión y la reserva de valor, provocó que una proporción cada vez mayor de la población trabajadora se vea imposibilitada de satisfacer su necesidad de acceso a una vivienda digna por la vía del consumo mercantilizado. Como consecuencia, surgieron diferentes formas alternativas de producción del hábitat que aglutinaron a diversos sujetos, abarcando desde trabajadores asalariados hasta personas desocupadas y en situación de extrema vulnerabilidad. Las iniciativas que llevaron a cabo estos actores se desarrollaron en las periferias este, norte y oeste; destacándose, especialmente, el barrio Movediza (Figura 1), debido a que allí surgió la mayor diversidad de experiencias vinculadas a la producción del hábitat por medio de la lógica de las necesidades sociales. De esta forma, dicho barrio se fue conformando en un espacio sumamente heterogéneo y representativo de los cambios ocurridos a lo largo de este período en lo respecta a las distintas estrategias y modalidades de acceso a la vivienda digna.

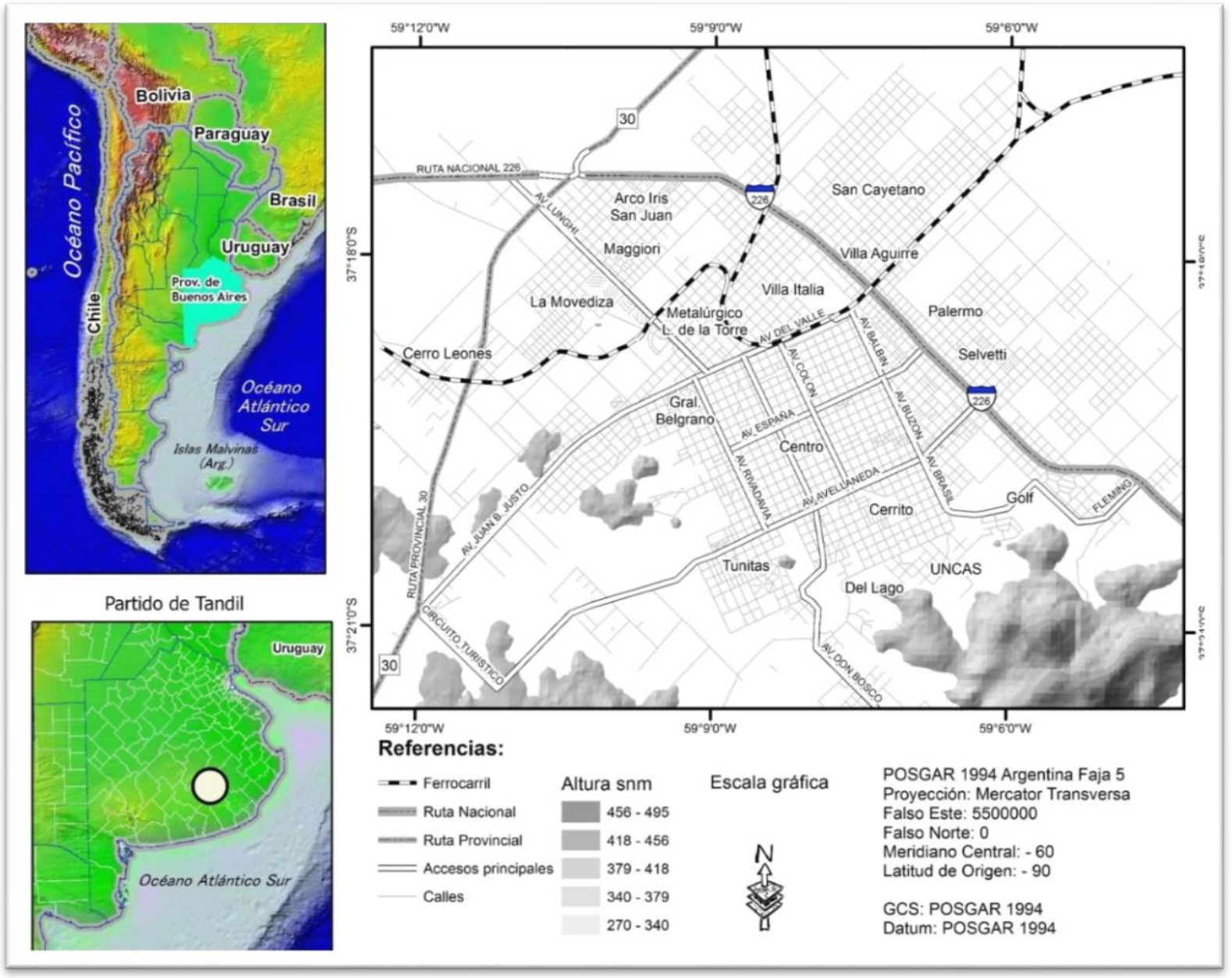

Figura 1: Tandil, ubicación de las sierras, principales barrios y vías de acceso a la ciudad. Fuente: Lan (2011, p. 31). 


\section{Consideraciones metodológicas}

Para abordar el objetivo formulado en este trabajo de investigación se optó por priorizar las técnicas propias del método cualitativo, especialmente las entrevistas semiestructuradas (técnicas de autoinformación) y las fuentes documentales. Las mismas permitieron acceder a los datos necesarios para estudiar los vínculos existentes entre las diferentes lógicas de producción del hábitat y su correspondiente materialización en el espacio del barrio Movediza.

En lo que se refiere a las entrevistas semi-estructuradas, se concretaron dos: una con la presidenta de la Asociación Civil Docentes, la cual se ha encargado de llevar a cabo una original iniciativa de producción de suelo urbano, que luego fue replicada por otras organizaciones en este mismo barrio; y la otra, a dos mujeres residentes del asentamiento Darío Santillán, que participaron de todo el proceso de consolidación y urbanización del lugar. La selección se basa en un tipo de muestreo intencional y opinático, donde el investigador selecciona a los informantes de acuerdo con un criterio estratégico personal (Ruíz Olagabuénaga, 1996), que en este caso se corresponde con el conocimiento de la situación que las entrevistadas poseen y que resulta relevante por haber participado en el proceso de gestión de cada una de estas experiencias. En lo que respecta a los lineamientos generales de las entrevistas, se consideró abordar tres grandes ejes: el proceso de organización de los actores involucrados en la urbanización y las estrategias empleadas para alcanzar sus objetivos, los motivos que llevaron a la construcción de sus espacios residenciales en el barrio Movediza y las vinculaciones establecidas con los organismos estatales para concretar sus iniciativas.

A su vez, se realizó una tercera entrevista semi-estructurada a una informante clave de la Secretaría de Desarrollo Social del Municipio. En este caso, la elección estuvo relacionada con la intención de conocer el resultado de las políticas habitacionales implementadas por los diferentes organismos del Estado en las últimas décadas en el barrio Movediza. También se profundizó en las acciones que se llevaron a cabo desde el gobierno local ante las sucesivas usurpaciones y las negociaciones que entablaron con los actores involucrados. Además, esta instancia sirvió para contrastar la información obtenida en las dos entrevistas anteriores.

En relación a las técnicas documentales, se recurrió al análisis de un documento brindado por la Secretaría de Desarrollo Social, que contiene una descripción pormenorizada de las políticas habitaciones que se llevaron a cabo en la ciudad de Tandil en las últimas décadas, detallando las operatorias, la cantidad de viviendas, los organismos intervinientes y la situación actual de los proyectos. Esta información permitió confeccionar una carta que presenta la situación actual del barrio Movediza, dando cuenta de la heterogeneidad de 
lógicas de producción del hábitat intervinientes. Para ello se utilizaron Sistemas de Información Geográfica.

Finalmente, también se utilizaron datos obtenidos de fuentes de información secundaria, para contextualizar la situación habitacional de la ciudad de Tandil y del barrio Movediza. Entre las mismas se incluyen: los Censos Nacionales de Población, Hogares y Viviendas, de los años 2001 y 2010; la Encuesta de Hogares y Empleo Municipal, del año 2018; el Registro Provincial de Villas y Asentamientos Precarios, del año 2016; y el Índice de Calidad de Vida, elaborado por Velázquez et al., en el año 2019.

\section{Producción del hábitat en el barrio Movediza: entre los vaivenes de la lógica pública y urgencia de la lógica de las necesidades}

El barrio Movediza constituye uno de los ejes de expansión más importantes de la ciudad en el período actual. Su acelerado crecimiento se encuentra ligado a los bajos valores relativos del suelo urbano y a la gran disponibilidad de tierras fiscales, que han sido destinatarias de políticas de vivienda social y también de la expansión del uso residencial por vía de la ocupación informal. Al observar el Índice de Calidad de Vida, es posible percibir que este barrio se encuentra entre los que poseen las peores condiciones materiales dentro de Tandil. Los valores de sus radios censales oscilan entre 7,03 y 7,16; presentando cifras similares a otros barrios periféricos de la ciudad, como Tunitas $(7,12)$, Palermo y Selvetti $(7,13)$, Villa Aguirre (entre 7,15 y 7,46) y Maggiori (entre 7,28 y 7,34). Estos números contrastan con los que se observan en el centro de la ciudad, que varían entre 8,50 y 8,84, y con aquellos que se registran en los barrios del sur: Cerrito (entre 8,60 y 8,79), Uncas (entre $8,63$ y 8,75$)$ y Golf $(8,94)$ (Velázquez et al., 2019).

La urbanización del barrio Movediza comenzó a acelerarse a partir de la década de 1990, con la implementación del Plan Familia Propietaria. Esta política, impulsada desde el gobierno provincial, tenía como objetivo inicial brindar subsidios a los municipios, mediante los cuales se comprarían y urbanizarían tierras, con la intención de otorgárselas a familias, que pudieran abonarlas a través de un plan de pagos de características flexibles (Coronel, 2019).

La modalidad original de esta política se desarrolló hasta el año 1999, pero luego una importante cantidad de conjuntos habitacionales pertenecientes a diversos programas estatales fueron construidos sobre dichos terrenos, debido a que parte del suelo generado no se había adjudicado o, en otros casos, sus beneficiarios habían perdido el derecho a la tenencia por incumplimiento de los requisitos exigidos. Asimismo, en las décadas de 2000 y 2010, la política continuó funcionando por medio de la afectación de lotes al programa, lo cual implicó la posibilidad de que muchos municipios pudiesen generar suelo urbano formal y con 
infraestructura mínima, eludiendo las rigideces que el Decreto-Ley 8.912 imponía para la regularización urbana (Marichelar, 2015).

Según Coronel (2019) en Tandil esta política se efectivizó entre 1993 y 1994, con la adquisición de tierras en los barrios Selvetti y Movediza. En el primero de estos, se accedió a un predio que se dividió en 48 lotes, mientras que en Movediza se compraron dos bloques de tierras, de los cuales surgieron 824 parcelas y dos espacios para equipamiento comunitario. En el año 1995, se realizó el sorteo por medio del cual se seleccionaron a las personas adjudicatarias, quienes debían comprometerse a edificar en el plazo de dos años y pagar la suma de $\$ 480$, en 24 cuotas de $\$ 20$. Sin embargo, en los siguientes años, se registraron numerosos incumplimientos que devinieron en la desafección de muchos de los adjudicatarios y en la reasignación de las parcelas a otras familias (Coronel, 2019).

A su vez, según mencionó esta misma informante clave, a lo largo de estos años en diversos terrenos pertenecientes a este programa, se registraron ventas y traspasos de adjudicatarios de manera irregular, frente a lo cual el Municipio intervino favoreciendo a quienes habían realizado esfuerzos para construir y habitar en dichas parcelas. Además, algunos de los programas que se desarrollaron entre finales de la década de 1990 y comienzos de los años 2000, como "24 casas comunitarias" y "Autoconstrucción y Ayuda Mutua", se realizaron sobre terrenos del Plan Familia Propietaria, que fueron liberados a raíz del incumplimiento de sus primeros adjudicatarios. Según la informante clave de Desarrollo Social, la crisis económica por la atravesaba el país en ese momento, generó que los resultados de la implementación de esta política fueran muy magros.

A partir del año 2005, comenzaron a realizarse las gestiones para la concreción de las operatorias correspondientes al Plan Federal de Construcción de Viviendas (PFCV). E mismo se materializó a través de la generación de dos conjuntos habitacionales: el "Plan Federal I, 139 viviendas" y el "Plan Federal II, 200 viviendas". Para la construcción de los mismos también resultó de fundamental importancia el Plan Familia Propietaria, debido a que, en este tipo de operatorias, eran los municipios quienes tenían la responsabilidad de gestionar el suelo urbano. De esta manera, el gobierno local optó por desvincular a los adjudicatarios que no habían cumplido con los requisitos exigidos, destinando los lotes liberados a los nuevos conjuntos de vivienda social.

Las obras del "Plan Federal I, 139 viviendas" comenzaron en el año 2005, mientras que las del "Plan Federal II, 200 viviendas", se iniciaron en 2008. Sin embargo, en 2009 se produjeron momentos de parálisis en el desarrollo de los proyectos, debido a las demoras que se registraron en la llegada de las partidas presupuestarias. Según la informante clave de la Secretaría de Desarrollo Social, este hecho, sumado al deterioro de la situación económica ocasionada por los efectos de la crisis financiera que se desató en el año 2008, 
provocó que la población del barrio Movediza que contaba con necesidades habitacionales insatisfechas, se viera impulsada a ocupar ilegalmente parte de las viviendas que se encontraban sin terminar. La informante clave lo explicó de la siguiente manera:

Dentro del mismo barrio la gente que trabajaba en la misma obra fue transmitiendo ese comentario de "Bueno, esto no lo terminan más", "Nosotros nos vamos y esto no lo terminan más" (...) Al no haber respuesta por parte del Estado frente a las necesidades que había y los altos alquileres, la gente que estaba alquilando... diferentes motivos llevaron a que una familia tomara esa decisión de ocupar un lote (Entrevista propia, 05/07/2016)

Para compensar esta situación, posteriormente se consiguió la firma de un convenio entre el Municipio, el Instituto Provincial de la Vivienda (IVBA) y el ANSES, para financiar otras 50 viviendas en lotes que se afectaron al Plan Familia Propietaria. Según la entrevistada, en esta obra también se produjeron ocupaciones, aunque luego se resolvieron debido a que los inmuebles ya estaban adjudicados. En síntesis, del "Plan Federal I, 139 viviendas" se entregaron, entre los años 2008 y 2014, 137 viviendas a sus adjudicatarios originales y sólo dos permanecieron ocupadas; mientras que del "Plan Federal II, 200 viviendas" se entregaron 106 entre 2010 y 2014; de las restantes, 54 fueron ocupadas y 40 no alcanzaron a iniciarse (Cuadro 1).

De esta forma, en las parcelas que originalmente fueron creadas mediante el Plan Familia Propietaria en el barrio Movediza se generó una compleja combinación de modalidades de producción y consumo del hábitat, a raíz de las marchas y contramarchas que registraron las trayectorias de las políticas públicas, y de las acciones de ocupación que ocurrieron a partir del año 2009. En este sentido, puede identificarse un primer momento, en la década de 1990, en la que se produjo suelo urbano mediante un proceso de desmercantilización estatal y diferentes modalidades de construcción de viviendas, que abarcaron procesos de desmercantilización social (autoconstrucción), de desmercantilización estatal (programas "24 casas comunitarias" y "Autoconstrucción y Ayuda Mutua") y producciones no mercantiles por encargo. Según Jaramillo (2012), estas últimas corresponden a las construcciones generadas por personas o grupos solventes que tienen la posibilidad de encargar la producción de la vivienda que utilizarán como bien de uso a un productor mercantil o mercantil simple ${ }^{3}$. En un segundo momento, que se extiende entre los

\footnotetext{
${ }^{3}$ Según Jaramillo (2012), la diferencia entre la producción mercantil y la producción mercantil simple, es que la última no está regida por el objetivo de la acumulación de capital, sino que el fin es obtener una suma monetaria con la intención de intercambiarla por otros bienes mercantiles para el consumo. Es decir, estos agentes producen y trabajan involucrados en relaciones mercantiles para mantener un determinado nivel de consumo y de reproducción humana. Sin embargo, los agentes capitalistas buscan obtener plusvalía y acumular capital, lo que, a su vez, conlleva otro tipo de racionalidad en la toma de decisiones y en los comportamientos adoptados.
} 
años 2005 y 2008, en la producción de las viviendas predominaron procesos de desmercantilización estatal, generados por las operatorias correspondientes al Plan Federal de Construcción de Viviendas. Finalmente, un tercer momento, a partir del año 2009, se caracterizó por una mayor diversidad de situaciones, debido a las acciones que implicaron la toma de viviendas y terrenos. A lo largo de estos años se observaron: 1) accesos no mercantiles (Pírez, 2016) mediante usurpaciones a terrenos y viviendas sin concluir, 2) producción desmercantilizada socialmente, sobre todo en aquellos casos en que los ocupantes terminaron las viviendas usurpadas o las construyeron sobre los terrenos tomados, y 3) producción desmercantilizada estatalmente, en aquellas situaciones en que el Estado pudo recuperar las viviendas y terminarlas.

Cuadro 1: Políticas habitacionales desarrolladas en Movediza, en las últimas tres décadas.

\begin{tabular}{|c|c|c|c|}
\hline Nombre & Cant. & Operatoria & Situación \\
\hline $\begin{array}{c}24 \text { casas } \\
\text { Comunitarias }\end{array}$ & 24 & $\begin{array}{l}\text { Fondo Municipal de } \\
\text { Vivienda }\end{array}$ & Se construyen en 1998 \\
\hline $\begin{array}{c}\text { Autogestión y Ayuda } \\
\text { Mutua I }\end{array}$ & 20 & $\begin{array}{l}\text { Convenio entre el } \\
\text { Consejo Provincial de } \\
\text { la Familia y Desarrollo } \\
\text { Humano, el IVBA y el } \\
\text { Municipio. }\end{array}$ & $\begin{array}{l}\text { Se construyen entre } 1998 \text { y } 2000 \text {, en } \\
\text { lotes del Plan Familia Propietaria } \\
\text { (PFP) }\end{array}$ \\
\hline $\begin{array}{c}\text { Autogestión y Ayuda } \\
\text { Mutua II }\end{array}$ & 4 & $\begin{array}{l}\text { Fondo Municipal de } \\
\text { Vivienda }\end{array}$ & $\begin{array}{l}\text { Se construyen entre } 2000 \text { y } 2001 \text {, en } \\
\text { lotes del PFP }\end{array}$ \\
\hline $\begin{array}{c}\text { Autoconstrucción y } \\
\text { Ayuda Mutua III }\end{array}$ & 20 & $\begin{array}{l}\text { Convenio entre el } \\
\text { Consejo Provincial de } \\
\text { la Familia y Desarrollo } \\
\text { Humano, el IVBA y el } \\
\text { Municipio. }\end{array}$ & $\begin{array}{l}\text { Se construyen entre } 2000 \text { y } 2004 \text {, en } \\
\text { lotes del PFP }\end{array}$ \\
\hline
\end{tabular}


Autoconstrucción y

Ayuda Mutua IV
2 Fondo Municipal de Vivienda
Se construyen entre 2001 y 2003 , en lotes del PFP
Autoconstrucción y

Ayuda Mutua V

20

Fondo Municipal de Vivienda
Se construyen entre 2000 y 2004 , en lotes del PFP

Plan de Emergencia

Plan Federal de

Emergencia

Habitacional
Hab. Techo y Trabajo

12

del Estado Nacional, más fondos provinciales y municipales

\section{Comienza en 2004: 4 viviendas}

finalizadas y 8 no lograron concluirse y fueron ocupadas
24 Casas

Comunitarias
24

Ministerio de Obras y Servicios Públicos

Realizado en 2006, en lotes del PFP

Plan Federal de

Construcción de

Viviendas I
139

Programa Federal 139 finalizadas, algunas con colaboración viviendas del Municipio. Dos viviendas sin terminar. Construidas en lotes del PFP
Plan Federal de

Construcción de Viviendas II
200

Programa Federal 200 viviendas

Del 2008 al 2014. Con 106 viviendas entregadas, 40 no construidas y el resto inconclusas. En lotes del PFP.

\section{Plan Federal}

Plurianual de Const. de Viv. Reconvertido
50

Convenio entre el

ANSES, el IVBA y el

Municipio
Finalizan en 2014. Construidas en lotes que luego se afectaron al PFP 
Programa Federal

Mejor Vivir

6

Mejor Vivir
Realizado entre 2005 y 2010 , construcción de módulos en 6 viviendas

Fuente: elaboración propia en base a datos suministrados por la Secretaría de Desarrollo Social del Municipio de Tandil (2016).

\section{Producción de asentamientos informales en el barrio Movediza: organización, gestión y negociación con el poder público}

Las sucesivas ocupaciones que comenzaron a registrarse desde el año 2009, no afectaron solamente a los terrenos asignados al Plan Familia Propietaria y a la construcción de las viviendas del Plan Federal. A partir del año 2011, también se produjeron ocupaciones de tierras contiguas a estas operatorias que, paulatinamente, fueron constituyendo un asentamiento informal. Mediante entrevistas realizadas a habitantes del lugar se pudo conocer que algunos de sus habitantes habían llegado luego de ser desalojados de terrenos usurpados previamente, mientras que otros arribaron como consecuencia de la imposibilidad de seguir pagando el alquiler de la vivienda en la que residían, debido al deterioro de su situación económica.

La llegada de las personas al asentamiento se produjo, fundamentalmente, en dos momentos. En el primero de ellos, el grupo de ocupantes estaba constituido, en gran medida, por inmigrantes extranjeros, razón por la cual el lugar comenzó a denominarse despetivamente como "la manzana de los paraguayos". Mientras que, en el segundo momento, que se generó a partir del año 2013, predominaron familias que provenían de otros barrios de la ciudad. Las informantes clave explicaron que el motivo que originó el arribo simultáneo de un grupo importante de personas fue la divulgación de cierta información, que precisaba que los lotes eran de origen fiscal y que, por lo tanto, resultaba improbable el desalojo.

La conformación del asentamiento requirió de cierto grado de acuerdo entre sus habitantes para definir criterios de distribución de la tierra y proveerse de determinados recursos básicos. Progresivamente, lograron instalarse respetando la cuadrícula del ejido urbano e intentando que los lotes se adapten a los requerimientos de la normativa urbana. Sin embargo, una de las entrevistadas explicó la incertidumbre por la que atravesaron en el primer período, a causa de la inestabilidad en la posesión de los terrenos: "Cada terreno tuvo varios dueños, es más a mí me corrieron tres veces...no venías dos días y ¡Chau!, agarraba otro" (Entrevista propia, 8/03/2016). Esta situación generó la necesidad de contar con un 
mayor nivel de organización, en pos de preservar la tenencia del suelo. En relación a este punto, otra de las vecinas explicaba:

Nos organizamos para que un vecino si podía te cuidara tu lote, pero había que armar enseguida algo. Nosotros cuando nos mudamos nos armamos la casilla, ella de madera y yo de chapa, estaban todos nuestros muebles ahí, entraba solamente la cama de dos plazas para mí y para mi marido y una cocinita, nada más, no quedaba más nada. Y tenías que quedarte ahí y lucharla. (Entrevista propia, 8/03/2016).

A su vez, las familias ocupantes recurrieron a diversas organizaciones y referentes sociales que colaboraron en la obtención de los servicios indispensables y, más adelante, en la formulación de un proyecto de regularización de los lotes. De esta forma, comenzaron un proceso de negociación pacífica con los funcionarios del gobierno municipal, por el que acordaron limitar el barrio a cuatro manzanas, reubicando en los terrenos libres a las familias que se encontraban dispersos en otros lotes.

Más adelante, se obtuvo la firma de un acuerdo, por el cual el Municipio se comprometió a que los 96 lotes ingresaran al Plan Familia Propietaria, para que los habitantes pudieran regularizar su situación y pagar los terrenos en cuotas. Además, desde la Secretaría de Desarrollo Social se entregaron bloques para la construcción, con el compromiso por parte de los ocupantes de sustituir sus casillas por viviendas de material en un plazo no mayor a dos años. Al momento de la entrevista, las familias del asentamiento ya poseían los planos realizados por los agrimensores, pero aún no habían comenzado con el proceso de regularización.

En los años siguientes, se produjeron otros episodios de tomas de terrenos de menores dimensiones, aunque la mayoría de ellos no lograron afianzarse. No obstante, recientemente se observó la consolidación de dos pequeños asentamientos. El primero de ellos, se ubica en un terreno que funcionó antiguamente como basural y que, posteriormente, fue rellenado, razón por la cual se lo conoce como "La Cava". Dicho lugar se encuentra dentro de las tierras que habían sido adquiridas originalmente por el Plan Familia Propietaria en la década de 1990 y estaba destinado a conformarse en uno de los espacios comunes que se habían proyectado para el barrio. El segundo, de origen más reciente, constituye un conjunto de construcciones extremadamente precarias que se extienden a lo largo de dos manzanas y que se ubica en el límite del ejido urbano. En el relevamiento realizado por el Re.Na.Ba.P., dicho asentamiento aparece con el nombre de "Movediza II".

En estas experiencias se observa un acceso al suelo urbano no mercantil (Pírez, 2016), aunque potencialmente en el caso del barrio Darío Santillán puede transformarse en un proceso desmercantilizado estatalmente, si es que las negociaciones con el Municipio 
prosperan y sus habitantes pueden pagar un valor por sus terrenos que les permita legalizar su situación. Asimismo, en lo que respecta a la construcción de las viviendas, se identifica un proceso dirigido por la lógica de las necesidades, aunque también intervienen elementos relacionados con la desmercantilización estatal, ya que el gobierno local ha contribuido con materiales, sin que esto implique un condicionamiento en la gestión que llevan adelante los pobladores. Por su parte, la dotación de infraestructura y servicios urbanos se ha conseguido mediante las distintas negociaciones entabladas con el Municipio, por lo que puede considerarse que se ha generado de forma desmercantilizada estatalmente. En los dos asentamientos conformados recientes, aún no se cuenta con infraestructura básica y tampoco se ha conocido que sus habitantes hayan accedido a ayudas de los organismos públicos para construir sus viviendas, con lo cual predominan procesos básicamente regidos por la lógica de las necesidades.

\section{Las asociaciones civiles y la producción desmercantilizada de sus proyectos residenciales}

Las características que fue adquiriendo el mercado inmobiliario de la ciudad de Tandil desde comienzos de la década de 2000, con la consecuente apreciación de los bienes inmuebles, alejaron cada vez más a ciertos grupos sociales de la posibilidad de acceder a la vivienda propia por las vías convencionales. Una de las respuestas que surgió ante dicha situación fue la constitución de la Asociación Civil Docentes, que se originó en el año 2010, a raíz de una iniciativa generada, fundamentalmente, por un pequeño grupo de trabajadoras de la educación, que decidieron organizarse a raíz de las dificultades que encontraban para solucionar este problema de manera individual. En poco tiempo, la organización fue creciendo e incorporando a un gran número de docentes que se encontraban insertos en instituciones educativas de los diferentes niveles de enseñanza de la ciudad. Estas trabajadoras, a pesar de ser asalariados registrados, resultaban excluidos del mercado de créditos por sus bajos salarios y, al mismo tiempo, tampoco ingresaban en los planes de vivienda social, porque no eran consideradas parte de la población más vulnerable. Ante tal panorama, la condición de inquilinas en la que se encontraban parecía prolongarse de manera indefinida.

En la búsqueda de una alternativa, se conformaron bajo la figura de asociación civil, que al poco tiempo trascendió el objetivo inicial del acceso al suelo urbano e incluyó una propuesta cultural, con una definición de hábitat de mayor profundidad. Para acceder al suelo con los recursos disponibles, la asociación debió encontrar un camino alternativo al que ofrecía el mercado formal. Esta situación implicó uno de los puntos más dificultosos del proceso, puesto que las únicas tierras disponibles a bajo costo eran las parcelas que lindaban con el ejido urbano, que al estar asignadas a usos rurales no podían subdividirse con 
objetivos residenciales. Finalmente, luego de un período de intensas gestiones, se logró un acuerdo con el gobierno municipal, por el cual la asociación adquirió seis hectáreas rurales contiguas al Bario Movediza y, luego, con la mediación del gobierno provincial, se propuso parcelar la tierra y afectarla al Plan Familia Propietaria. Como contrapartida, los docentes realizarían las obras para la urbanización de los terrenos.

Esta modalidad, permitió que los integrantes del proyecto adquirieran la tierra por un costo siete veces menor al de las parcelas vecinas, categorizadas como urbanas. Posteriormente, la asociación replicó la experiencia en lotes contiguos, alcanzando un total de 210 familias beneficiadas. La construcción de las viviendas se desarrolló de manera individual, siendo muchos de los integrantes de la asociación beneficiarios del crédito Pro.Cre.Ar., con lo cual se generó una combinación específica entre la generación del suelo urbano mediante las gestiones realizadas por la asociación civil y la adjudicación de los lotes al Plan Familia Propietaria, más la construcción de las viviendas mediante el programa de créditos hipotecarios que lanzó el gobierno nacional, en el año 2012. En la actualidad, las obras de urbanización se encuentran finalizadas, pero aún se observa que la proporción de integrantes que pudieron construir es relativamente baja, en parte debido a las dificultades económicas que se generaron en estos últimos años en el contexto nacional y que impactó directamente en la suba de los precios de los materiales de la construcción y en la caída del poder adquisitivo de los salarios.

A raíz de estos resultados, el gobierno local decidió promover la iniciativa para que otras organizaciones emprendan el mismo camino, tomando como modelo el proyecto de la Asociación Civil Docentes. Esto se tradujo en la aprobación de la Ordenanza 13.579, en noviembre de 2013. A su vez, el Municipio puso a disposición de algunas asociaciones que se conformaron a raíz de esta normativa una serie de lotes fiscales, que se encuentran contiguos a la Asociación Civil Docentes (Figura 2). De esta forma, actualmente existen otras seis organizaciones que están desarrollando proyectos de urbanización: Asociación Mutual de Empleados Municipales de Tandil, Cáritas San Cayetano, Coopteba Tandil, Unión de Educadores de Tandil, Consejo Pastoral Tandil y Cooperativa de Trabajo Cerámica Blanca.

En esta forma particular de producción también interfieren las diferentes lógicas, aunque, al menos en el caso de la Asociación Civil Docentes, la gestión siempre estuvo dirigida por los actores pertenecientes a las necesidades sociales, ya que fue la comisión de esta organización la que tomó las decisiones fundamentales en cada etapa. En lo que respecta a la generación del suelo urbano, se observa un proceso de desmercantilización social, generado a través del financiamiento que surge de la propia organización, pero, a su vez, también fue necesario el acuerdo con el Municipio para encontrar un mecanismo singular que les permitiese comprar tierra, que hasta ese momento no se encontraba dentro del ejido 
urbano y, posteriormente, también se utilizó el Plan Familia Propietaria para realizar la subdivisión del bloque. Con lo cual, también intervinieron elementos relacionados con la desmercantilización estatal.

Muchas de las viviendas realizadas en la asociación se generaron mediante el financiamiento otorgado por el programa de créditos Pro.Cre.Ar, con lo cual aquí también se generó un subsidio al consumo por parte del Estado. Finalmente, la infraestructura y los servicios fueron solventados, en gran medida, por la propia asociación, con los ingresos obtenidos de las cuotas mensuales y, adicionalmente, por algunas ayudas brindadas por el Municipio, que permitió abaratar el costo de las obras.

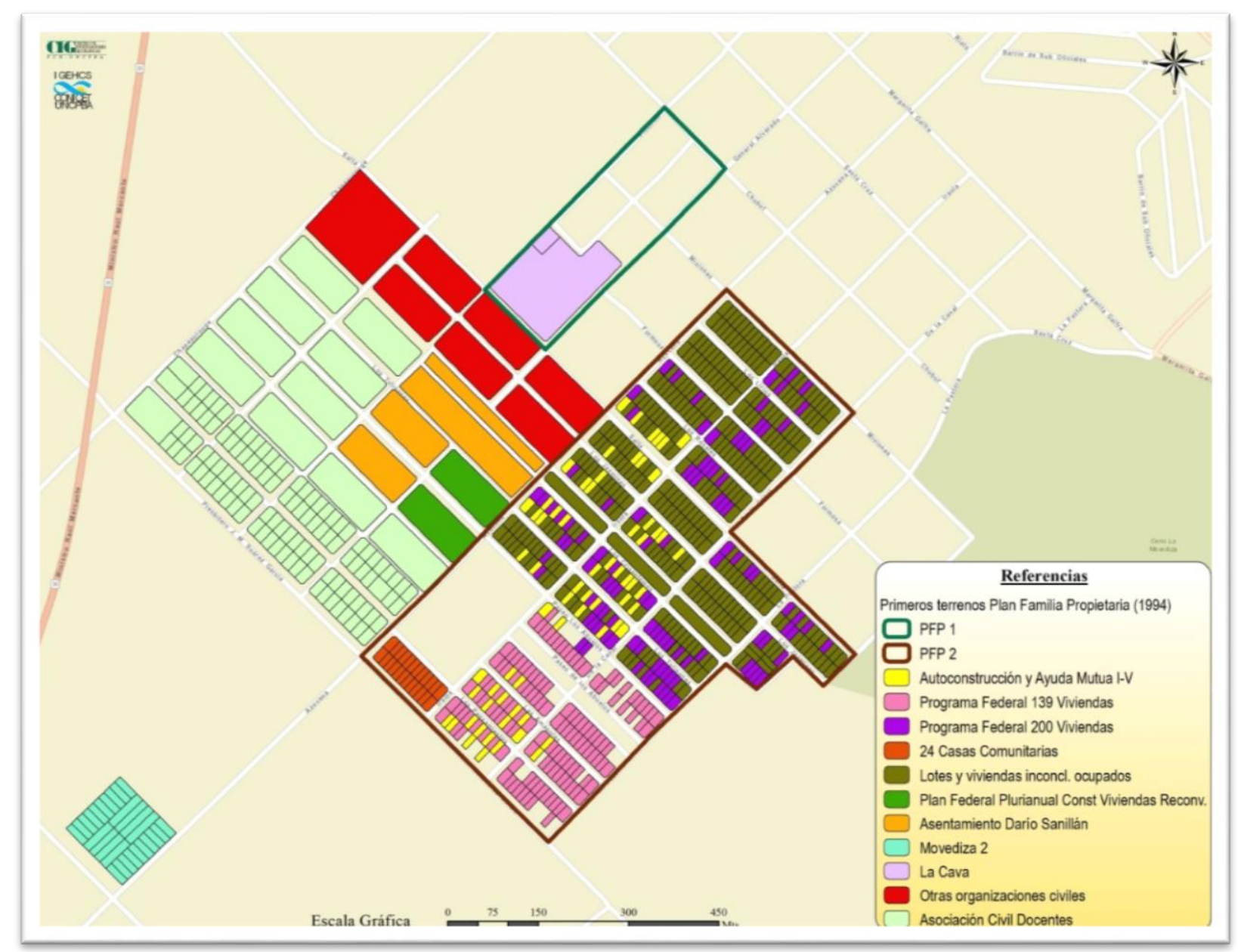

Figura 2: Diversidad de situaciones habitacionales en el barrio Movediza, año 2019.

Fuente: elaboración propia en base a datos suministrados por la Secretaría de Desarrollo Social del Municipio de Tandil (2016).

\section{Reflexiones finales}

Al igual que lo que ocurrió en el contexto nacional, en la ciudad de Tandil en las últimas dos décadas se observó el predominio de un modelo de urbanización excluyente, en el que 
persistieron los principales mecanismos de funcionamiento del mercado inmobiliario, que actuaron potenciando el valor financiero de los bienes raíces. Frente a las crecientes restricciones impuestas por el mercado inmobiliario formal, surgieron diversas estrategias alternativas de acceso al hábitat, que no eran habituales en esta ciudad intermedia en períodos anteriores. En este sentido, el barrio Movediza se volvió crucial para la concreción de estas iniciativas, debido a la existencia de una gran cantidad de lotes fiscales y de terrenos de propiedad privada con bajos valores relativos.

La iniciativa del gobierno municipal, que eligió este barrio para la generación de los lotes creados mediante el programa Plan Familia Propietaria durante la década de 1990, resultó decisiva, ya que posteriormente condicionó el lugar de emplazamiento de los conjuntos habitacionales construidos mediante las distintas operatorias públicas. A su vez, la parálisis de las obras correspondientes al Plan Federal y el deterioro de la situación económica que se experimentó en el año 2009, propiciaron que este lugar se convierta en objeto de disputa entre los poderes públicos y los grupos de vecinos que comenzaron a usurpar terrenos y viviendas sin concluir. Paulatinamente, se fue conformando un espacio heterogéneo en el que se alternaron viviendas producidas por los programas de vivienda social con otras construcciones, que fueron finalizadas por sus propios habitantes, una vez que se consolidaron las ocupaciones.

Posteriormente, surgió el asentamiento informal Darío Santillán, en el que se observó un proceso de urbanización que desde el origen estuvo regido por la lógica de las necesidades. A pesar de ello, sus habitantes mantuvieron un diálogo permanente con los funcionarios municipales, alcanzando los acuerdos que les permitieron concretar las obras de infraestructura y llevar adelante un proceso de regularización dominial. A su vez, los proyectos de urbanización que desarrollaron las asociaciones civiles también se encuadran dentro de las lógicas de las necesidades, aunque el proceso fue muy distinto al que se generó en el asentamiento. Sin embargo, se observan como denominadores comunes la articulación permanente que las organizaciones mantuvieron con el Municipio y la afectación de los lotes al Plan Familia Propietaria, mediante el cual se logró destrabar el problema de la subdivisión de las tierras, que anteriormente estaban asignadas al uso rural. La proliferación de asociaciones civiles en la ciudad, con el objetivo de generar suelo urbano más accesible, también da cuenta de la restricción que el mercado inmobiliario formal comenzó a generar sobre trabajadores que, aun siendo asalariados formales, quedaron al margen del acceso al consumo mercantilizado.

Finalmente, cabe mencionar que en estas experiencias se identifican ciertas particularidades que corresponden a la escala de una ciudad intermedia. Especialmente, se destaca la presencia de los diferentes organismos del Estado en todas las estrategias que se 
desarrollaron desde la lógica de las necesidades. Esta intervención abarcó desde el otorgamiento de materiales para que los ocupantes puedan finalizar sus viviendas, hasta los acuerdos para regularizar la situación de informalidad del suelo en el caso de los asentamientos y también para viabilizar el proyecto de urbanización en las asociaciones civiles. En este sentido, si bien la gestión de los procesos estuvo a cargo de actores pertenecientes a la lógica de las necesidades, los organismos públicos tuvieron la posibilidad de encauzar la urbanización y generar algunas pautas mínimas de ordenamiento en los nuevos barrios.

De esta manera, se observa que las características que adquirió el modelo de urbanización excluyente en la ciudad de Tandil, a lo largo de las últimas dos décadas, produjo la aparición de las primeras formas organizadas de producción del hábitat desmercantilizadas socialmente. Si bien en momentos anteriores existían algunos asentamientos informales, no se encontraron registros de que los mismos se hayan originado mediante algún tipo de organización colectiva, como sí ocurrió con el barrio Darío Santillán. Con lo cual, la agudización del valor financiero de los bienes inmuebles parece impulsar la conformación de un espacio urbano con formas mucho más heterogéneas de producción del hábitat, a raíz del carácter cada vez más restrictivo que presenta el mercado inmobiliario formal.

\section{Referencias Bibliográficas}

Abramo, P. (2011). La producción de las ciudades Latinoamericanas: mercado inmobiliario y estructura urbana. Quito: Olacchi.

Coronel, V. (2019). Apropiaciones y contradicciones del Plan Familia Propietaria en el Partido de Tandil (Tesis de Maestría). Facultad de Arquitectura, Urbanismo y Diseño, Universidad Nacional de Mar del Plata, Mar del Plata, Argentina.

Clichevsky, N. (2009). Algunas reflexiones sobre la informalidad y regularización del suelo urbano. En Bitácora urbano/territorial, 14 (1), 63-88.

de Mattos, C. (2007). Globalización, negocios inmobiliarios y transformación urbana. Nueva Sociedad, 1 (212), 82-96.

del Río, J. P. (2014). Transformaciones habitacionales en la Región Metropolitana de Buenos Aires. El pasaje del neoliberalismo al neodesarrollismo urbano. Geograficando, 10 (2), 1-33.

Engels, F. ([1873] 2006). Contribución al problema de la vivienda. Madrid: Fundación Federico Engels. 
Fernández Wagner, R. (2014). Los límites de las políticas neo keinesianas en el desarrollo urbano y vivienda. En D. Gargantini (comp.), Hábitat, acceso al suelo y financiamiento. Experiencias alternativas de producción socio-habitacional (pp: 29-38). Córdoba: Universidad Nacional de Córdoba.

Jaramillo, S. (2012). Urbanización Informal: Diagnósticos y políticas. Una revisión al debate latinoamericano para pensar líneas de acción actuales. Documentos CEDE (Centro de Estudios sobre Desarrollo Económico, Facultad de Economía, Universidad de los Andes). https://ideas.repec.org/p/col/000089/009820.html

Lan, D. (2011). Territorio, industria, trabajo: división territorial del trabajo y espacio producido en la industria de la ciudad de Tandil (Tesis doctoral). Facultad de Humanidades y Ciencias de la Educación, Universidad Nacional de La Plata, La Plata, Argentina.

Ortiz Florez, E. (2012). Producción social de vivienda y hábitat: bases conceptuales para una política pública. En El camino posible, producción social del hábitat en América Latina (pp. 13-40). Montevideo, Uruguay: Trilce/Centro Cooperativo Sueco.

Pírez, P. (1995). Actores sociales y gestión de la ciudad. Ciudades. Gestión urbana y poder local 1(28), 1-12.

Pírez, P. (2014). Mercantilización y desmercantilización de las metrópolis latinoamericanas.

América Latina en Movimiento. La cuestión urbana hoy: entre el mercado total y el buen vivir, 1(497), 3-6.

Pírez, P. (2016). Las heterogéneas formas de producción y consumo de la urbanización latinoamericana. Quid, Revista del Área de Estudios Urbanos del Instituto Gino Germani, 16 (6), 131-167.

Pradilla Cobos, E. (2014). La ciudad capitalista en el patrón neoliberal de acumulación en América Latina. En Cadernos Metrópole 16 (31), 37-60.

Rodríguez, M. C., Di Virgilio, M. M., Procupez, V., Vio, M., Ostuni, F., Mendoza, M. y B. Morales (2007). Producción social del hábitat y políticas en el Área Metropolitana de Buenos Aires: Historia con desencuentros. Buenos Aires: Instituto de Investigaciones Gino Germani, Facultad de Ciencias Sociales, Universidad de Buenos Aires.

Ruíz Olagabuénaga, J. I. (1996). Metodología de la investigación cualitativa. Bilbao: Universidad de Deusto. 
Segura, Ramiro. (2014) El espacio urbano y la (re)producción de desigualdades sociales. Desacoples entre distribución del ingreso y patrones de urbanización en ciudades latinoamericanas. Working Paper Series 1(65), 1 - 31.

Topalov, C. ([1979] 2006). La urbanización capitalista. México: Editorial Edicol.

Velázquez, G.; Zunino, A.; Mikkelsen, C.; Linares, S.; Celemín, J. P.; La Macchia, L.; Manzano, F.; Tisnés, A. (2019). Dime dónde resides y te diré cuán bien (o mal) vives. Consejo Nacional de Investigaciones Científicas y Técnicas. https://www.conicet.gov.ar/dime-donde-resides-y-te-dire-cuan-bien-o-mal-vives/

\section{Otros documentos consultados}

Catenazzi, A. y Reese, E. (2013). Derecho a la ciudad. La dinámica de crecimiento urbano, el déficit habitacional y las asignaturas pendientes. Voces en el Fénix. https://www.pagina12.com.ar/especiales/archivo/voces_en_el_fenix/002-fenix.pdf

Decreto 902/2012 del Poder Ejecutivo Nacional de la República Argentina. Créase el Fondo Fiduciario Público denominado Programa Crédito Argentino del Bicentenario para la Vivienda Única Familiar.

http://servicios.infoleg.gob.ar/infolegInternet/anexos/195000199999/198531/norma.htm

En Tandil, cerca del 60 por ciento de los vecinos es dueño de su casa y un 30 por ciento alquila (21 de septiembre de 2019). El Eco de Tandil.

https://www.eleco.com.ar/la-ciudad/en-tandil-cerca-del-60-por-ciento-de-losvecinos-es-dueno-de-su-casa-y-un-30-por-ciento-alquila/

Instituto Nacional de Estadísticas y Censos - INDEC (2001). Censo Nacional de Población, Hogares y Viviendas 2001. https://redatam.indec.gob.ar/argbin/RpWebEngine.exe/PortalAction?\&MODE=M AIN\&BASE=CPV2001ARG\&MAIN=WebServerMain.inl

Instituto Nacional de Estadísticas y Censos - INDEC (2010). Censo Nacional de Población, Hogares y Viviendas 2010.

https://redatam.indec.gob.ar/argbin/RpWebEngine.exe/PortalAction?\&MODE=M AIN\&BASE $=$ CPV2010B\&MAIN=WebServerMain.inl

Marichelar, G. (2015). Políticas habitacionales y políticas urbanas, una relación conflictiva.

En VII Seminario Internacional de Investigación en Urbanismo, BarcelonaMontevideo. https://upcommons.upc.edu/handle/2117/81107 
Municipio de Tandil (2005). Plan de Desarrollo Territorial Tandil.

https://www.argentina.gob.ar/interior/secretaria-de-planificacion-territorial-ycoordinacion-de-obra-publica/planes-locales/buenosaires

Secretaría de Desarrollo Social del Municipio de Tandil (2016). Barrios Tandil, proyectos realizados mediante operatorias estatales. 7 páginas.

Subsecretaría Social de Tierras, Urbanismo y Vivienda del Ministerio de Infraestructura y Servicios Públicos de la Prov. de Bs. As. (2016). Registro Público Provincial de Villas y Asentamientos Precarios. http://190.188.234.6/mapa/ 